\title{
A novel method of triple stenting in patients with malignant hilar biliary obstruction: triple stenting abreast method
}

An 85-year-old woman visited our hospital with obstructive jaundice. Contrastenhanced computed tomography (CT) showed a gallbladder tumor, multiple liver tumors, and intrahepatic bile duct dilatation ( $\mathbf{F i g . 1}$ ). Hepatic tumor biopsy showed adenocarcinoma. The final diagnosis was gallbladder cancer, multiple liver metastases, and malignant hepatic hilar biliary obstruction (MHBO) due to liver invasion. She underwent endoscopic retrograde cholangiopancreatography with placement of self-expandable metal stents (SEMS) for obstructive jaundice because she hoped for best supportive care ( $>$ Video 1 ).

A TJF-Q290V duodenal scope (Olympus Medical, Tokyo, Japan) was used. Three 0.025-inch guidewires (M-through; Medico's Hirata Medical, Osaka, Japan) were inserted into the anterior and posterior bile ducts of the right robe, and the left bile duct over the strictures. A novel, uncovered, laser-cut, metal stent with 5.4-Fr ultrathin delivery system (Zeo stent V; Zeon Medical, Tokyo, Japan) was used. Three metal stent delivery systems were simultaneously inserted over the guidewires with olive oil after dilation of the strictures in the anterior bile duct of the right robe and left bile duct (REN $8 \mathrm{~mm}$; Kaneka Medical, Osaka, Japan) ( Fig.2a). The stents were released one by one and placed with their distal ends at the same level above the papilla of Vater ( $\triangleright$ Fig. 2 b). On the next day, plain CT confirmed no stent migration ( $>$ Fig. 3 ).

Placement of SEMS is recommended for MHBO because of their longer patency compared with plastic stents. Recently, side-by-side and stent-in-stent methods of bilateral SEMS placement have been applied for cholangitis in two or more segments. The use of three or more metal stents is technically challenging and makes reintervention difficult. The
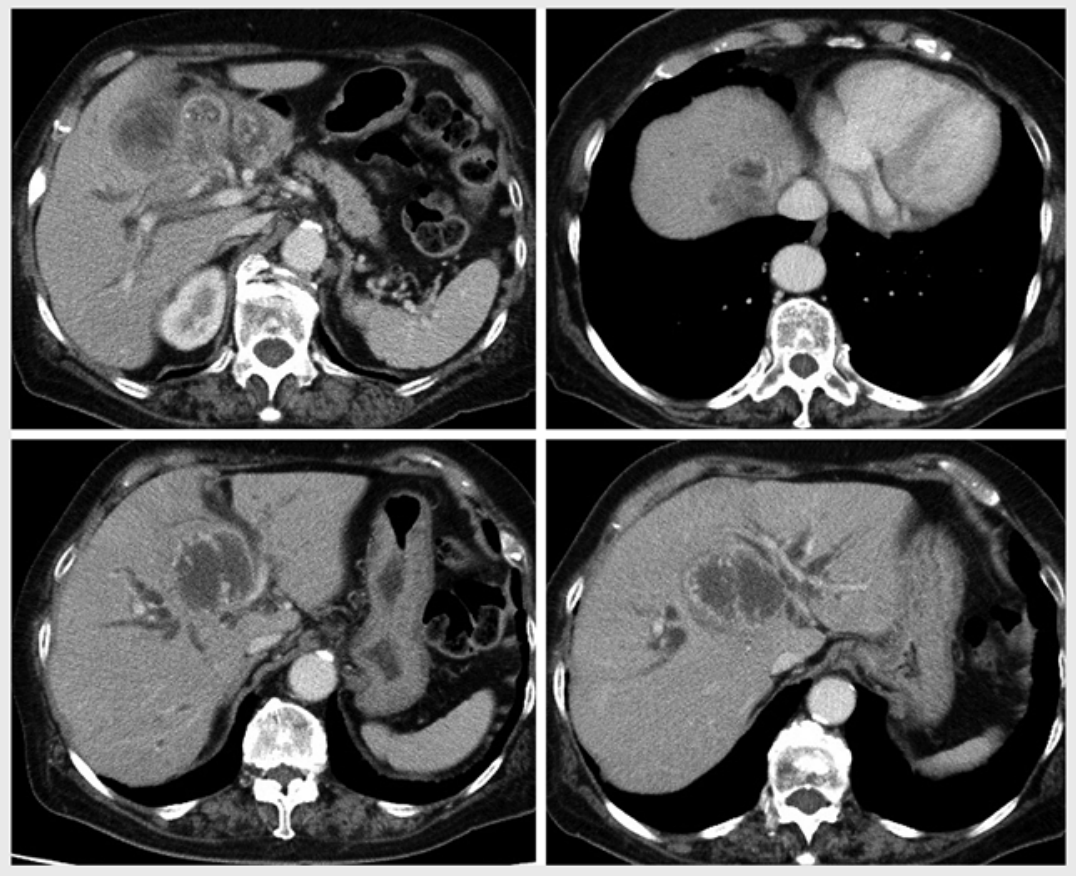

Fig. 1 Contrast-enhanced computed tomography showed a gallbladder tumor, multiple liver tumors, and intrahepatic bile duct dilatation.

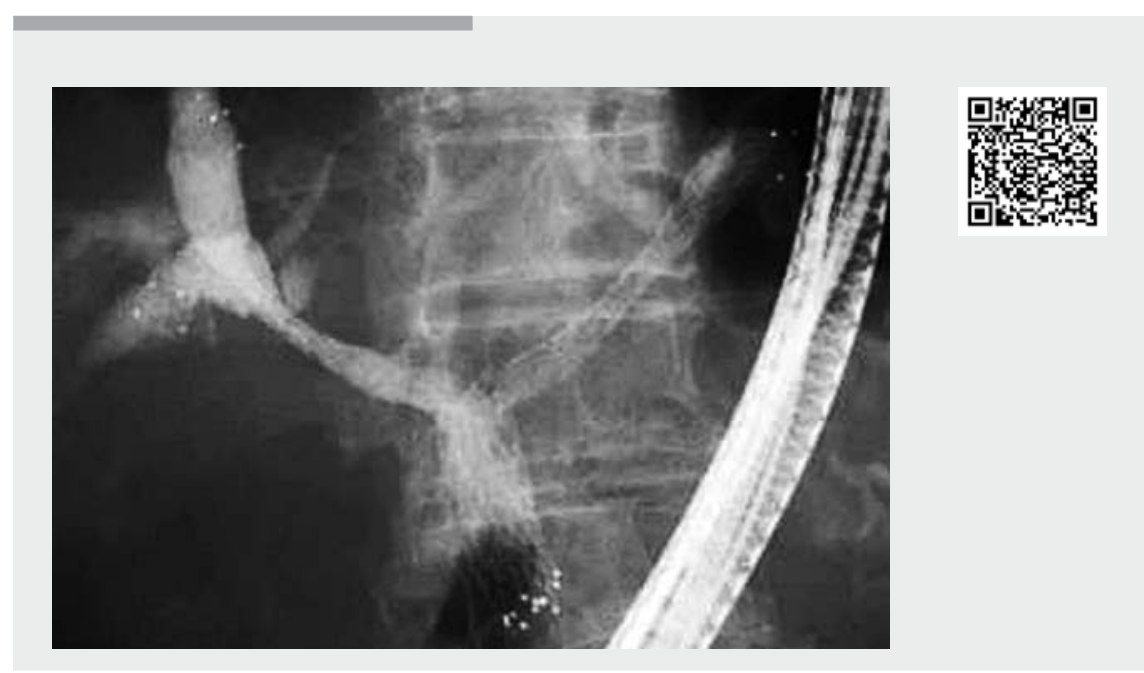

Video 1 Triple stenting abreast method for malignant hilar biliary obstruction. 

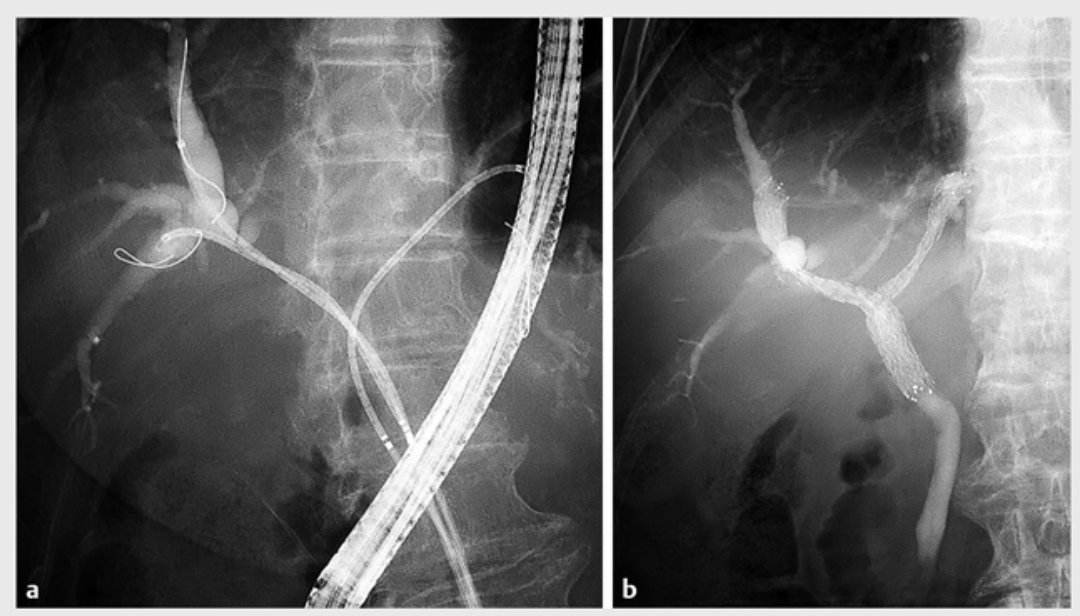

- Fig. 2 Fluoroscopic images. a Three metal stent delivery systems were simultaneously inserted over the guidewires. b The stents were placed with their distal ends at the same level above the papilla of Vater.
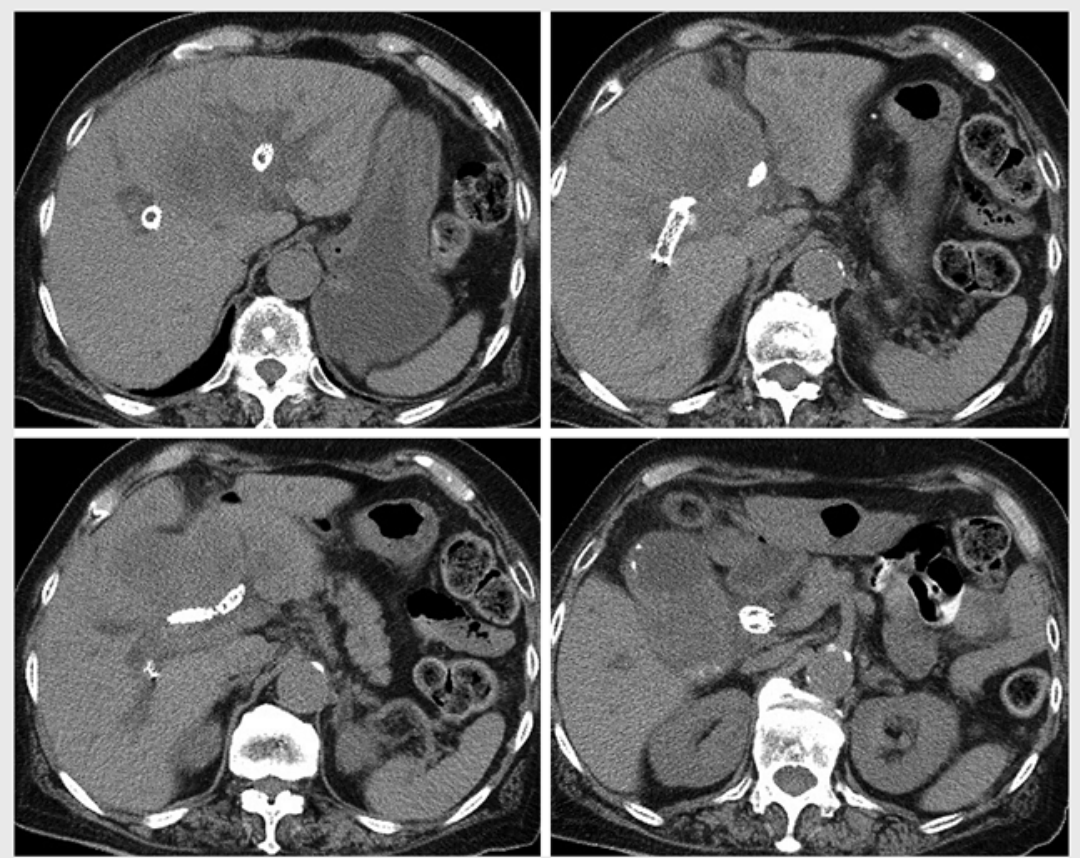

Fig. 3 Plain computed tomography showed no migration of the stents.

triple stenting abreast (TSA) method is not a time-consuming technique and reintervention is straightforward. The use of the 5.4-Fr ultrathin delivery system facilitates this novel method. The
TSA method offers several benefits for patients with unresectable MHBO requiring multiple stenting.

Endoscopy_UCTN_Code_TTT_1AR_2AZ
Competing interests

The authors declare that they have no conflict of interest.

The authors

Masanari Sekine, Junichi Fujiwara, Hirosato Mashima

Department of Gastroenterology, Saitama

Medical Center, Jichi Medical University

\section{Corresponding author}

\section{Masanari Sekine, MD, PhD}

Department of Gastroenterology, Saitama Medical Center, Jichi Medical University, 1-847, Amanuma-cho, Omiya-ku, Saitama City, Saitama 330-8503, Japan Fax: +81-48-6485188

msekine@jichi.ac.jp

\section{Bibliography}

DOI https://doi.org/10.1055/a-1108-1337

Published online: 17.2.2020

Endoscopy 2020; 52: E295-E296

(c) Georg Thieme Verlag KG

Stuttgart · New York

ISSN 0013-726X

\section{ENDOSCOPY E-VIDEOS}

https://eref.thieme.de/e-videos

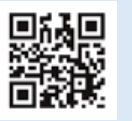

Endoscopy E-Videos is a free access online section, reporting on interesting cases and new techniques in gastroenterological endoscopy. All papers include a high quality video and all contributions are freely accessible online.

This section has its own submission website at

https://mc.manuscriptcentral.com/e-videos 